\title{
Transboundary cooperation a potential route to sustainable development in the Indus Basin
}

\author{
Adriano Vinca ${ }^{\mathrm{a}, \mathrm{b}, *}$, Simon Parkinson ${ }^{\mathrm{a}, \mathrm{b}}$, Keywan Riahi $^{\mathrm{a}, \mathrm{c}, \mathrm{b}}$, Edward Byers ${ }^{\mathrm{a}}$, Afreen Siddiqi ${ }^{\mathrm{d}, \mathrm{g}}$, \\ Abubakr Muhammad $^{\mathrm{e}}$, Ansir Ilyas ${ }^{\mathrm{e}}$, Nithiyanandam Yogeswaran ${ }^{\mathrm{f}}$, Barbara Willaarts ${ }^{\mathrm{a}}$, Piotr \\ Magnuszewski $^{\mathrm{a}}$, Muhammad Awais ${ }^{\mathrm{a}, \mathrm{b}}$, Andrew Rowe ${ }^{\mathrm{b}}$, Ned Djilali ${ }^{\mathrm{b}, \mathrm{h}}$ \\ ${ }^{a}$ International Institute for Applied Systems Analysis, Austria \\ ${ }^{b}$ Institute for Integrated Energy Systems, University of Victoria, BC, Canada \\ ${ }^{c}$ Institute for Thermal Engineering, TU Graz, Austria \\ ${ }^{d}$ Massachusetts Institute of Technology, Cambridge, MA, USA \\ ${ }^{e}$ Center for Water Informatics $\mathcal{E}$ Technology, Lahore University of Management Sciences, Lahore, Pakistan \\ ${ }^{f}$ TERI School of Advanced Studies, New Delhi, India \\ ${ }^{g}$ Harvard Kennedy School, Cambridge, MA, USA \\ ${ }^{h}$ Institute of Engineering Thermophysics, School of Energy and Power Engineering, Chongqing University, China
}

\begin{abstract}
To feed a rapidly growing population of 250 million, the Indus river basin in South Asia is one of the most intensively cultivated regions on Earth, highly water stressed and lacking energy security. Yet, most studies advising sustainable development policy have lacked multi-sectoral and cross-country perspectives. Here we show how the Indus countries could lower costs for development and reduce soil pollution and water stress, by cooperating on water resources and electricity and food production. According to this analysis, Indus basin countries need to ramp up investments to 10 billion USD/year to mitigate water scarcity issues and ensure improved access to resources by 2050. These costs could shrink to 2 billion USD/year, with economic gains for all, if countries pursued more collaborative policies. Downstream regions would benefit the most, with reduced food and energy costs and better water access, while upstream regions would benefit from new energy investments. Using integrated water-energy-land analysis, this study quantifies the potential benefits for novel avenues to sustainable development arising from greater international cooperation.
\end{abstract}

Keywords:

Water; Energy; Land; Food; Climate; Indus River Basin; International Cooperation, Sustainable Development; Investments

\footnotetext{
*Corresponding author. Email address: vinca@iiasa.ac.at
} 
The Indus river basin is home to about 250 million people of which $61 \%$ live in Pakistan, 35\% in India, 4\% in Afghanistan and less than $1 \%$ in China [1, 2]. The basin encompasses the largest glacier area in Asia, covering over half a million square kilometers of mountains and providing, together with precipitation a precious water resource of about $287 \mathrm{~km}^{3} /$ year [3]. Agriculture is the main economic activity, employing half the population to generate a quarter of the basin GDP [4]. With the most extensive irrigation canal system in the world, agriculture is responsible for up to $95 \%$ diversion of available freshwater in the basin [1, 5, 6].

Water scarcity has long been a critical problem, causing river dry-out in the Indus Delta, soil salinization and exploitation of groundwater; consequences that local administrations struggle to manage [7-9]. Agricultural practices, namely crop-type shift, crop rotation and water and energyuse efficient irrigation technologies can help reduce water stress, but require investment, education and organizational resources. Fresh water availability is also tightly related to the operation of hydropower plants and reservoirs, which must balance prescribed allocations of the Indus Water Treaty (IWT) with challenges in controlling seasonal droughts and floods [10, 11].

In the coming decades, population and water, energy, food and land demand will grow and climate change is already altering water availability, posing multi-dimensional challenges to development and sustenance in the region [12]. Additionally, political tensions related to resources within and across countries in the region further adds to the challenges.

River flow allocation to the six main tributaries of the Indus river between Pakistan and India is currently governed by the Indus Water Treaty, which is considered one of the most enduring international agreements for water resources [13]. But new challenges are now emerging. For instance, the IWT has provisions for dispute resolution and arbitration, but lacks trust-building mechanisms such as adequate data-sharing. As the impacts of climate change manifest, the issue of trust, allocation, and co-operation will gain new saliency for Pakistan and India in particular, but also for Afghanistan and to a limited extent, China [11, 14].

Other large basins around the world deal with challenges of large scale river diversions, food and energy security and international cooperation similar to the Indus basin (i.e. Nile and Ganges) [15-17]. The United Nation Sustainable Development Goals (SDGs) provides a framework to help governments and stakeholders tackle such challenges and inform policy intervention in individual 
sectors [18, 19]. However, climate, land, energy and water (CLEW) systems are highly coupled and qualitative methods need to be complemented with integrated approaches to understand and assess multiple cross-sector feedbacks [20-22].

CLEW studies and Indus-basin applied research to date have been mostly water-centric and with gaps in either energy, climate or land cross-sectoral feedbacks [23-27]. Furthermore, current analyses focus on local or national solutions, without accounting for the transboundary nature of basins or the opportunities that international collaboration could offer in basin-wide solutions [7, 28].

Here, we present a quantitative scenario-based analysis that captures synergies and trade-offs within the water, energy, land and climate systems of the Indus Basin. Uniquely, we offer a perspective that focuses on the entire basin beyond national borders, exploring the possibility of joint investments in food and electricity production, as well as open market of shared resources. We show how improved cross-border cooperation on electricity, water trade and crop shift among riparian countries has the possibility of bringing economic, social and environmental benefits for regional development. Previous studies address transboundary cooperation issues between CLEWS sectors within the context of the Water Convention [29, 30]. However, Indus countries lack a framework to promote transboundary discussion on sensitive topics as shared-resource management.

The approach also advances existing research on cooperation issues, in which water and energy resources, electricity market and greenhouse gas (GHG) emission mitigation are considered as segregated areas with disparate scales in time and space (i.e. water conflicts involve riparian countries, energy and food markets are global) [31-34]. Connection between sectors are particularly evident in the Indus basin, for example linkages of virtual water involved in food trade, and flood management, food production and electricity generation that are linked through multipurpose and nationally-administrated dams [35, 36]. This study explores what maybe be possible with transboundary cooperation in these sectors.

We use a modelling framework that links hydrological modelling with engineering-economic capacity planning (NEST [37]), and we study a set of long term scenarios to 2050 (see Table 1). By comparing the developments of water, energy and agriculture sectors in a Business-as-usual (BAU) pathway with a scenario with sustainability targets $(S D G)$, we assess the investment gaps to achieve the targets, and we quantify several associated socio-environmental co-benefits. The investment 
gap for the basin (summing new investments in some sectors and disinvestment in others) amounts to only $13 \%$ of total annual expenditures. In the case of the SDG scenario, we investigate the additional benefits of increased cooperation (SDG-coop). The $S D G$-coop scenario explores the pathways to achieve the same targets as the $S D G$ scenario with specific cooperative mechanisms: cross-border electricity trade driven by electricity market prices; basin-wide food market to meet demands, as opposed to domestic production assumed in the $B A U$ and SDG scenarios; and river flow allocation to guarantee environmental flow targets, water access and lowest cost for agriculture production across the whole basin.

We find that cooperation, in all the analyzed scenarios, is the most beneficial solution to all Indus countries, even when taking into account uncertainties through a sensitivity analysis. Therefore, it would be worth for regional policy makers to explore and pursue more cooperative strategies.

\section{Towards Sustainable Development Goals (SDGs)}
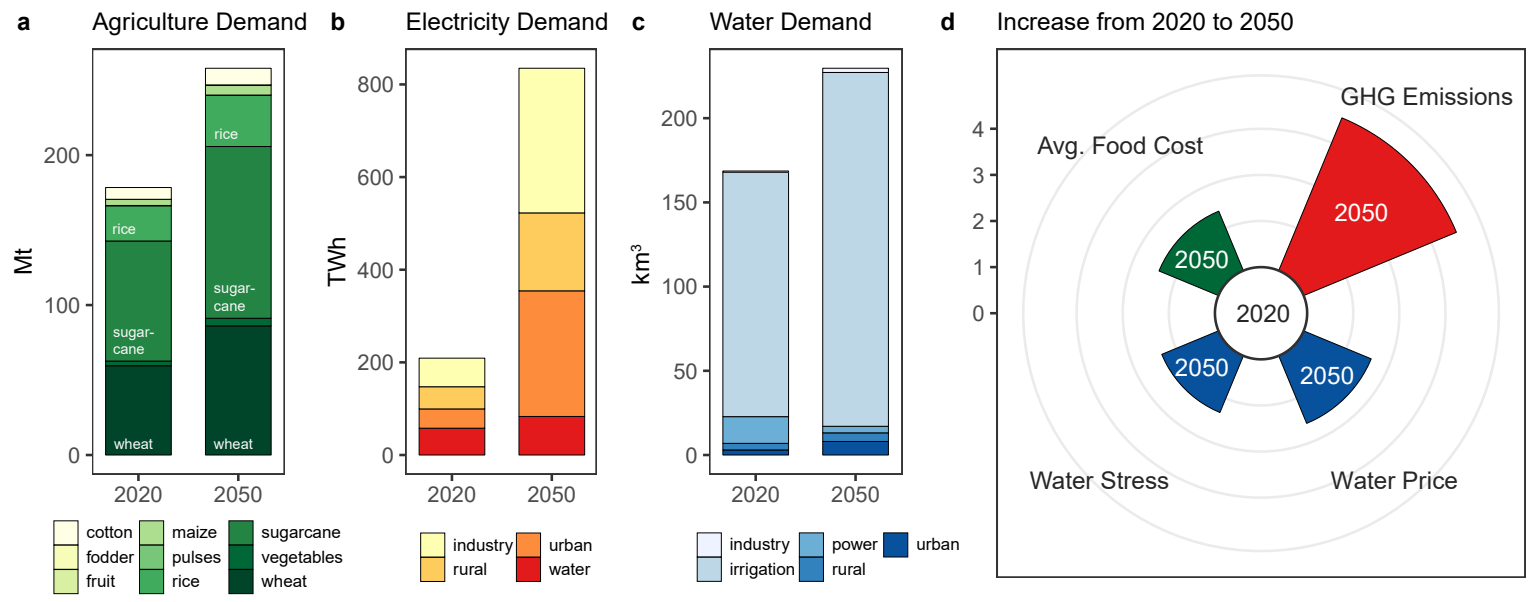

Figure 1: Expected Indus basin demands growth from 2020 to 2050 in, agriculture products (a); electricity (b) and water (c). X-fold increase from 2020 to 2050 in cumulative GHG emissions, freshwater prices, water stress (as calculated in Figure 2, and average food cost (d).

Although all nations committed to the SDGs in 2015, first we consider the case that might occur in absence of progress on the SDGs - Business As Usual. Currently, about $55 \%$ of electricity in the basin is produced from fossil fuels, hydropower production is underexploited and renewable energy generation is less than $5 \%$ of total production [37, 38]. We estimate a fourfold rise in electricity demand in the basin by 2050 compared to 2020 driven by population growth and improved 
electricity access. The $B A U$ scenario with a continuation of historical trends and current energy policies (expansion of hydropower and phase out of coal, Figure S[5], would result in a fourfold increase in GHG emission related to oil and gas consumption, augmenting the regional contribution to climate change (Figure $1 \mathrm{~b}$ and d ). Simultaneously, based on FAO projections, demand for agricultural products will rise by 45\% between 2020 and 2050 (Figure 19). In the absence of water efficiency measures in agriculture, the withdrawals will exceed $220 \mathrm{~km}^{3} / y e a r$ (versus the current $180 \mathrm{~km}^{3}[1]$ ), and water prices, food production costs and water stress will more than double (Figure 1tc and d). The regions of Punjab (both Indian and Pakistani) and the lower regions (Sindh in Pakistan), which already struggle with water scarcity [8], would overexploit renewable water sources by up to $250 \%$ in 2050 (Figure 2). This poses challenges not only to farmers, but also to urban areas that will suffer from reduced water access [39]. Improvements in irrigation efficiency with subsidies to drip, sprinkler and smart monitoring technologies can significantly reduce water losses related to unproductive evaporation. Water consumption can be consequently lessened if irrigation efficiency policies are supported by withdrawals regulation [40, 41]. In addition, achieving the SDG targets will entail improved clean water and sanitation accessibility for about 127 Million people [42].
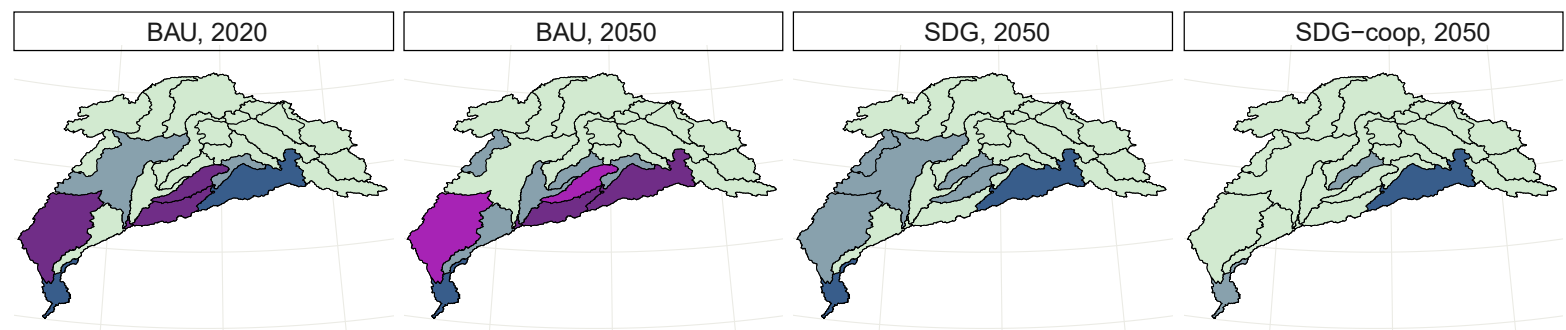

WSI: withdrawals/ mean available renewable water

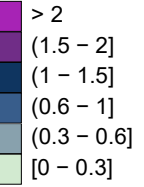

$$
\begin{array}{ll}
\text { WSI }>1 & \text { Overexploited/ deprived of river flow } \\
0.6>\text { WSI } \geq 1 & \text { Heavily exploited } \\
0.3>\text { WSI } \geq 0.6 & \text { Moderately exploited } \\
\text { WSI } \leq 0.3 & \text { Slightly exploited }
\end{array}
$$

Figure 2: Maps of annual Water Stress indicator (WSI) in the Indus basin in the $B A U$ in 2020 and 2050, and values for 2020 for $S D G$ and $S D G$-coop scenarios. A map with region's names is shown in Figure S[1. Basin delineation from HydroSHEDS [43]

To meet and sustain progress on the SDGs through to 2050, will mean coping with the rapid increase of access to limited resources and the growing demands across all sectors. Thus, we 
defined a set of ambitious targets for each sector (summarized in Table 1), based on scientific information and informed by direct consultation with local stakeholders, along with co-producing a compatible modelling framework (see Supplementary Methods on stakeholders engagement and co-production). Starting from the most urgent problem of controlling water withdrawals -to ensure domestic water access and minimum river flows required to protect the rich ecosystem of the Indus Delta [9]- we constrain future agriculture withdrawals to not exceed current levels (about $150 \mathrm{~km}^{3}$ per year). We set minimum environmental flow requirements (in average $10 \mathrm{~km}^{3} / \mathrm{year}$, [44]) and set a reasonable goal of $95 \%$ access to sanitation in the whole region [42].

We characterized the remaining targets by consulting local experts (see Supplementary Methods), setting at least 50\% deployment of efficient irrigation, and 90\% carbon-free electricity generation, this would entail incentivizing decentralized electricity production with solar PV or minihydro to reduce energy poverty [45].

Pursuing these targets requires a set of long-term measures, namely increased investment in efficient irrigation; crop relocation within countries to maximize yields while minimizing water consumption; expansion of piped water distribution and increase of wastewater recycling; shift from fossil fuel-based electricity generation to more distributed renewable sources; and management of large storage to concurrently meet energy demand and minimum river flow requirements.

The net basin cost change (investments and operational costs) induced by these measures amounts to 10 billion USD/year (see cost assumptions in Methods and SI). This is $13 \%$ more than the overall system costs of 75 billion USD/year in Business-as-usual (as a reference, this is one quarter of Pakistani GDP in 2017, which is for 80\% included in the basin [46], Figure 3 a).

In particular, Pakistan needs to invest 4 and 0.6 billion USD/year in water distribution and treatment respectively. Internal crop relocation could save the country 3 billion USD/year while reducing water withdrawals. The energy measures would require a shifting 4 billion USD/year in oil and gas to 7 billion USD/year investments in more distributed renewable energies, which could save more than 1 billion USD/year in electricity transmission. India would need to invest in water distribution and treatment (1.3 and 0.4 billion USD/year respectively) and about 3 billion USD/year in efficient irrigation technologies, but require only marginal changes in the energy sector. Afghanistan requires similar investment trends, although proportionally smaller, namely 313 and 84 million USD/year in water distribution and treatment, but also 540 million USD/year 
in renewable energy, which is $40 \%$ of the total cost increase in the region (Figure 3b).

A number of socio-environmental co-benefits are direct consequence of new measures and investments (Figure 3r). Increased irrigation efficiency and optimal crop shift lower irrigation surface and groundwater use per ton of crop product in 2050 by $30 \%$. Land pollutants drop by $40 \%$ due to reduced cultivated land and fertilizer use. Investments in water distribution and treatment policies enable sanitation access to 127 million people by 2050 and increase availability of water that can be re-used for domestic purposes. Water saving measures help reduce river depletion and water stress across the whole basin (Figure 2). The shift from fossil-fueled electricity to renewable sources has clear impacts on air pollution and GHG emissions (85\% and 65\% reduction respectively), as well as on water consumption for power plant cooling (Figure 3 ).

Some socio-economic benefits are not directly embedded in our modelling framework, for example the positive effect of decentralized electricity production with solar PV or mini-hydro on energy poverty [45]. Therefore, we can state that some advantages of achieving sustainability goals may be here underestimated. Also, socio-environmental benefits are heterogeneous across countries. Figure S[9 shows overall positive trends across all Indus countries and indicators when achieving the goals in the $S D G$ scenario.

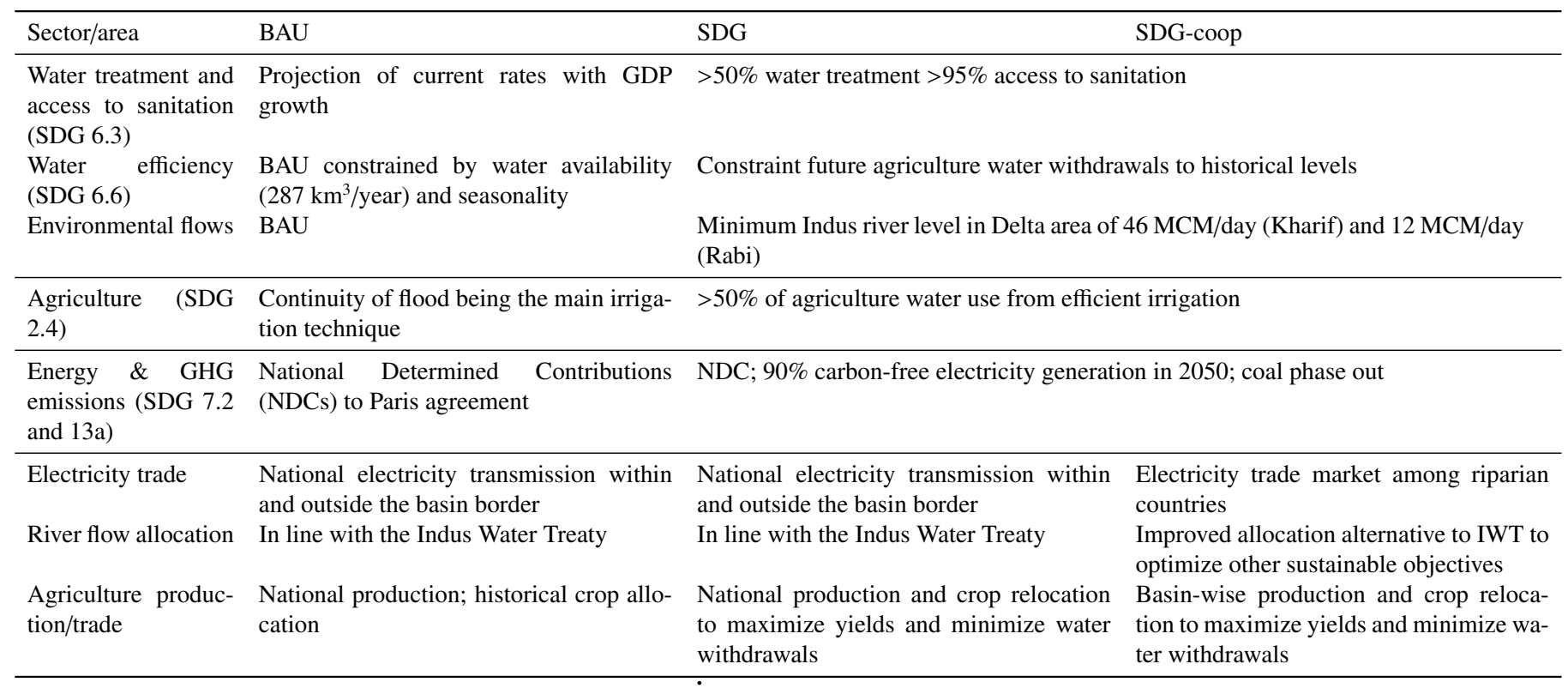

Table 1: Scenario assumptions for $B A U S D G$, and $S D G$-coop, in addition to common assumptions for all scenarios, Table S[1] 


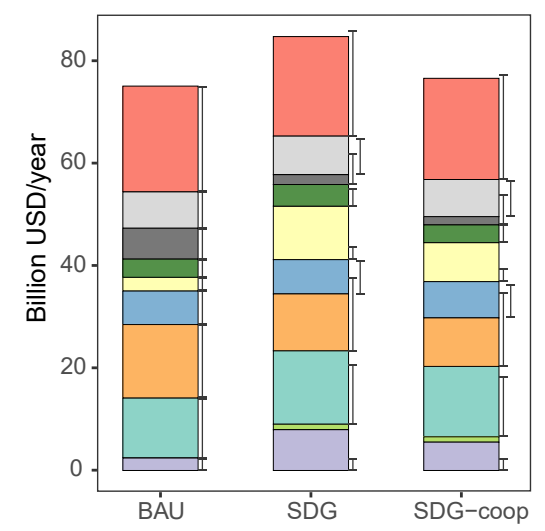

b Country expenditure difference from BAU to SDG

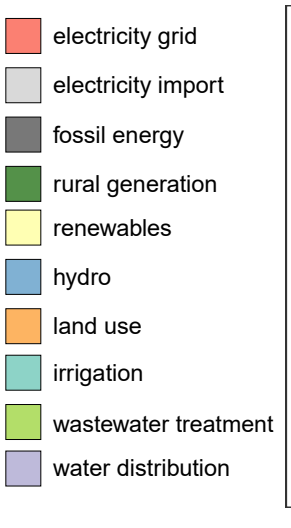

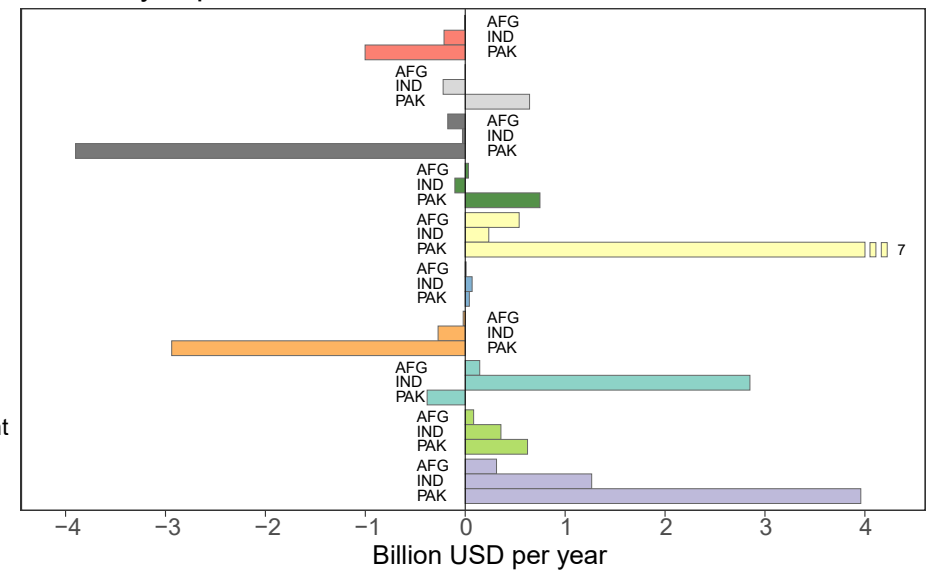

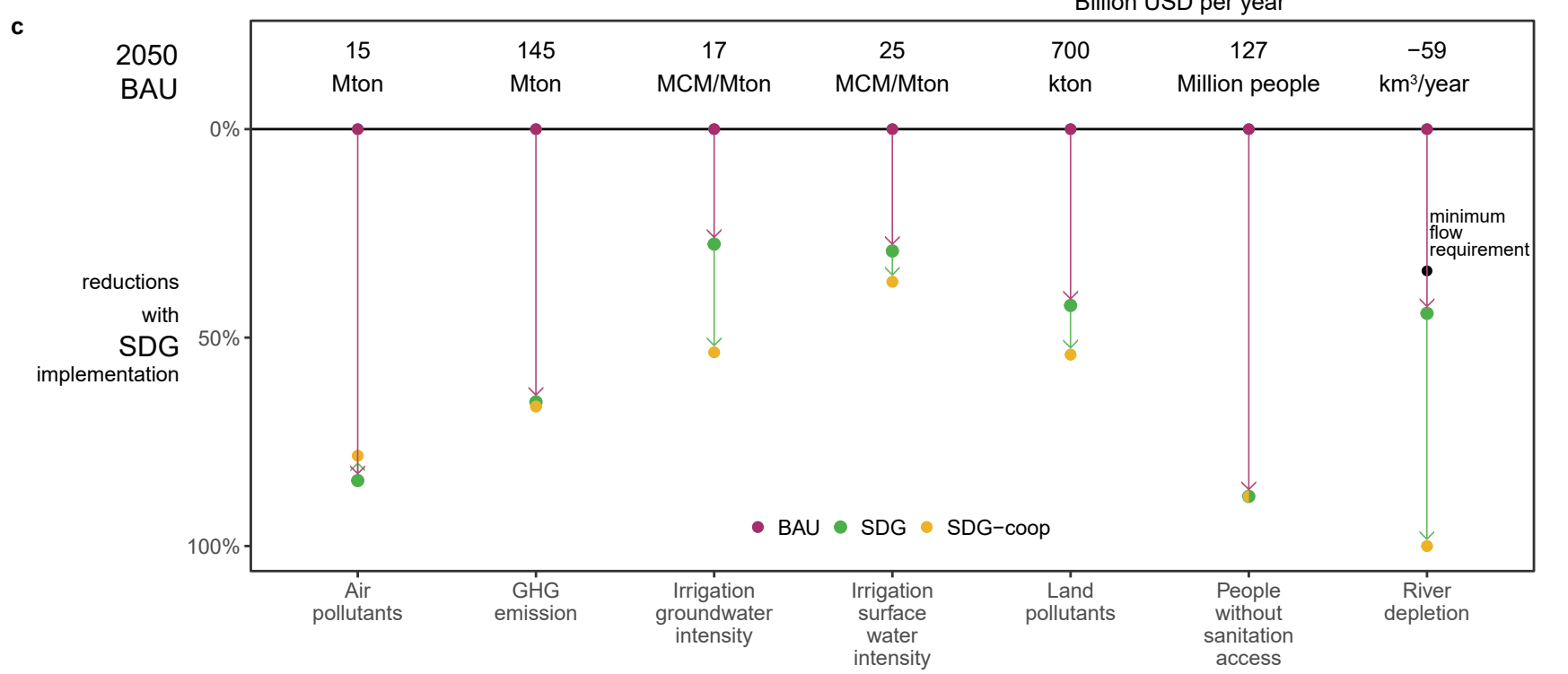

Figure 3: Total basin average yearly costs (investments + Operational and Maintenance), USD2010 are used in this analysis. Sectors: electricity transmission and distribution; domestic electricity import from regions not included in the basin, fossil-fueled energy generation; rural diesel or solar energy production; solar, wind or biomass generation; large and small hydropower; land cost, machinery and fertilizers; irrigation technologies (flood, drip, sprinkler and canals); wastewater treatment; water extraction, diversion and distribution. Error bars show $B A U$ values (a); Total cost changes between $S D G$ and $B A U$ scenario by country, changes refer to areas within the basin boundary (b); Sectorial socio-environmental benefits of $S D G$ and $S D G$-coop scenarios with respect to $B A U$ in 2050 . The $0 \%$ axis and labeled values refer to $B A U$, arrows and other dots represent the reductions for other scenarios. Indicators: cumulative air pollutants' emissions from electricity generation and land use $\left(\mathrm{SO}_{2}, \mathrm{CO}, \mathrm{NH}_{3}, \mathrm{VOC}\right)$; cumulative $\mathrm{CO}_{2}$ equivalent emitted; average surface and groundwater use per unit of crop product; cumulative release of pollutants from fertilizers $\left(\mathrm{K}_{2} \mathrm{O}, \mathrm{N}, \mathrm{N}_{2} \mathrm{O}, \mathrm{P}_{2} \mathrm{O}_{5}, \mathrm{VOC}\right)$; number of people without access to sanitation and clean water; difference between lowest and highest discharge river level across scenarios (c). 


\section{Role of cooperation}

From a systemic point of view all countries gain when pursuing the cooperation strategies identified in this study. Total basin costs for achieving the targets in the SDG scenario would be $9 \%$ lower ( 8 billion USD/year less) if cooperation on energy, agriculture and water management was implemented. Thus, the additional system costs for sustainability targets would be only 2 billion USD/year above $B A U$, instead of 10 billion USD/year (Figure 3 a, see Figure S 8 for country differences). Overall, the changes embedded in the cooperation scenario clearly lead to environmental and efficiency benefits. Surface and groundwater intensity in irrigation, as well as land pollutants and river depletion will further reduce compared to the $S D G$ scenario, augmenting the benefits of achieving sustainability targets (Figure 3 F). On the other hand, the improvements in energy-related indicators, such as GHG emission and air pollutants, remain similar with or without cross-country cooperation.

The electricity generation portfolio in 2050 and electricity trade between countries suggests that about 66 TWh of solar energy produced in lower Pakistan would be replaced by less costly electricity from hydropower, geothermal and solar PV in India in the SDG and SDG-coop scenarios (Figure 4a). Also, abundant hydroelectric energy available in upper Pakistan, normally only used domestically, is provided to the nearest regions of Afghanistan and India in the SDG-coop scenario. This might pose challenges for Pakistan energy security, especially in case of climate change affecting water resources, and will be further explored with sensitivity cases. This shift would also require new investments in energy production in the Indian part of the basin. As a consequence of these changes, and accounting for the different average expenditure net of trade costs $($ inv $+O \& M+\Delta$ trade $)$ in the two scenarios, Pakistan would save 5 billion USD/year. Electricity production costs for India would increase of 1.3 billion USD/year, but the country would attract new investments and build a more robust power sector.

Enhancing cross-border food trade reveals that if production of $23 \mathrm{Mt}$ of wheat and $16 \mathrm{Mt}$ of rice from lower Pakistan is shifted to India, where water costs are lower, there would be overall improved utilization of water (Figure $4 \mathrm{~b}$ ). This strategy would result in trade-net savings for all the riparian countries, with Pakistan and Afghanistan benefiting the most (1750 and 300 million USD/year respectively) and very marginal savings for India. This also raises political acceptability concerns addressed in more detail in the following section. 
From a water conveyance perspective, the alternative water allocation resulting from the abovementioned production shifts (which differs from IWT allocations, as in Figure 4c) could save significant investment in Indian canals than internally redistribute water to match domestic demand (overall more than 2.4 billion USD/year savings for India). At the same time, this would reduce water costs for the other riparian countries, allowing significantly higher inflows to Pakistan and reducing water stress in the whole basin (Figure 4k and d).

In summary, taking a transboundary, cooperative approach that relies on increased electricity and food production on the upper parts of the basin, is demonstrably a win-win strategy: being both cost effective and delivering environmental benefits across the board (Figure $4 \mathrm{~d}$ ). From a country by country perspective, Pakistan and Afghanistan see an overall economic benefit of cooperation across all sectors of about 7.75 and 0.43 billion USD/year respectively (around $15 \%$ of total cost to achieve SDG targets for both countries). But India could also save 1.15 billion USD/year (3.2\% of Indian annual costs) by redistributing costs from water distribution to energy production (Figure 4d). Also in this case, the actual economic benefits would be higher than what estimated here, if the beneficial environmental impacts were to be monetized. Finally, we also notice that the SDGcoop scenario yields improvements in the environmental indicators for the entire region and across all countries, except for GHG emissions and land pollutants in India related to cooperative shift in energy and food production (Figure S[9].

\section{Discussion}

This study demonstrates that cross-boundary cooperation among riparian countries in the Indus basin could enable sustainable development at $9 \%$ lower costs than without cooperation and with additional socio-environmental benefits, primarily lowering water stress in the regions of Kabul, Punjab and Sindh from heavily-moderately to slightly exploited water resources. The various benefits are of major importance for policy making and incentive planning. All can gain, if the management of shared resources and investment planning would go beyond country-centric visions.

While water agreements are currently in place and electricity trade plans have also been discussed between Indus countries [47], the idea of large de-localization of food production might be politically difficult, since policy makers are mainly focused on food self-sufficiency and security. 

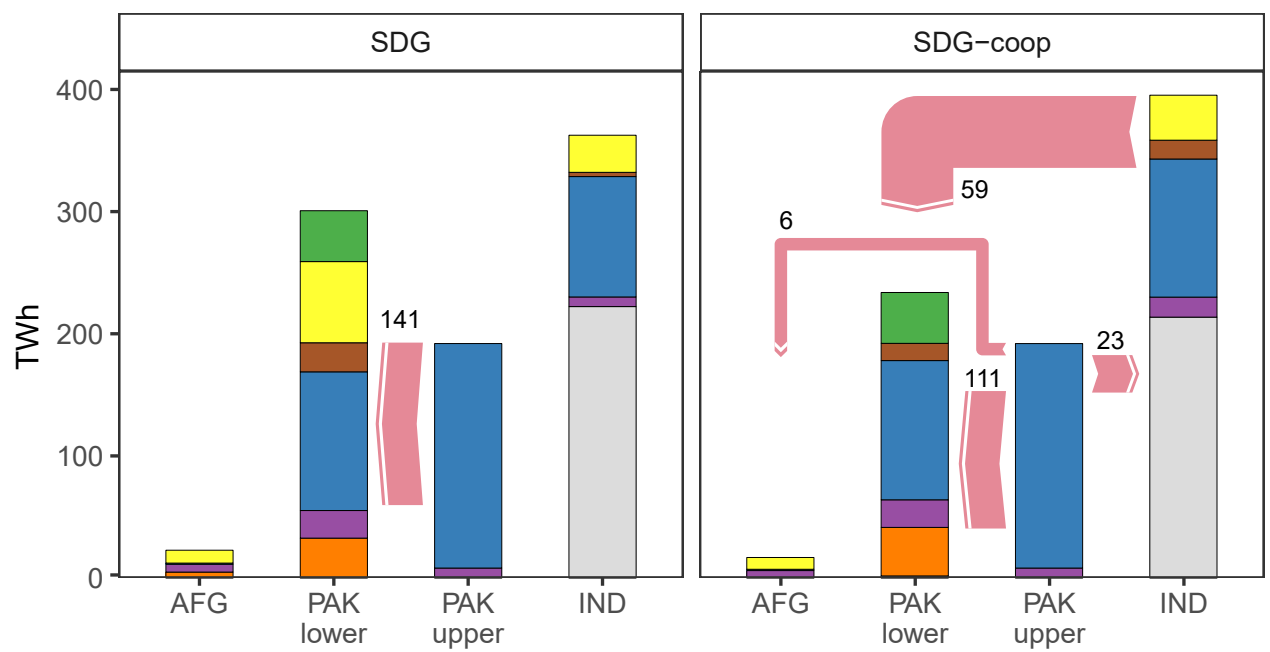

wind

solar rural gen.

hydro geothermal

gas

oil

import

rest India

b Crop production and trade in 2050
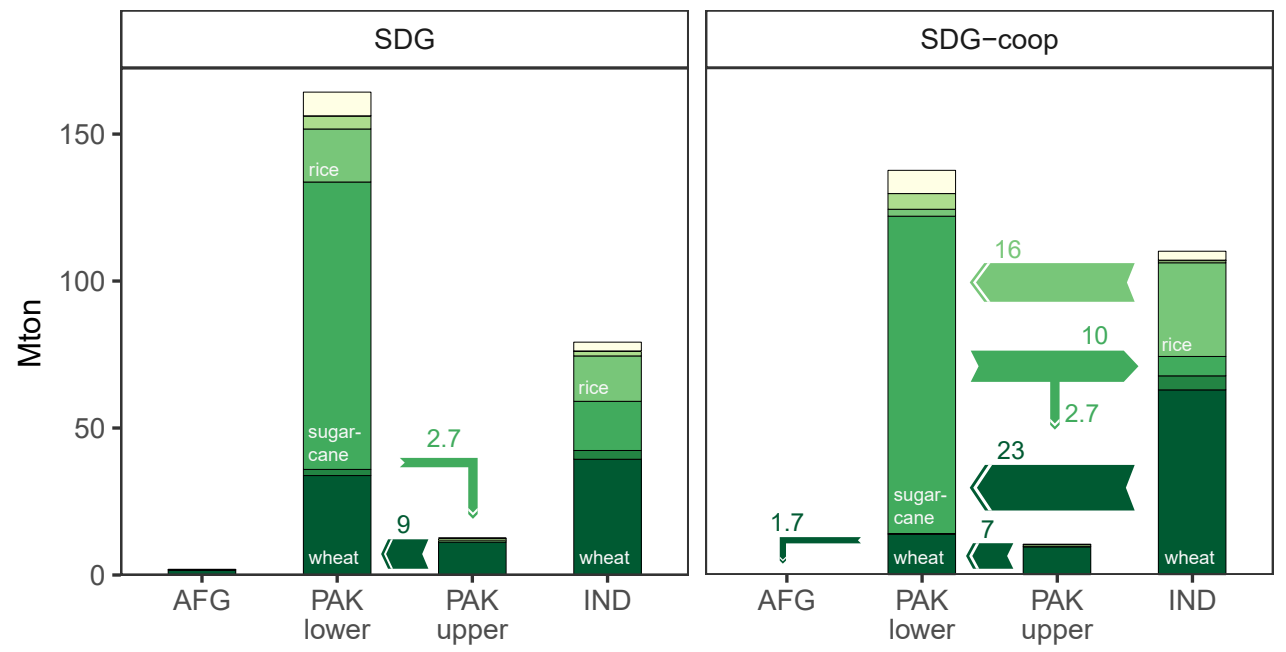

cotton

fruit

pulses

maize

rice

sugarcane

vegetables

wheat

c River flow changes in 2050 with cooperation d Overall annual savings with cooperation
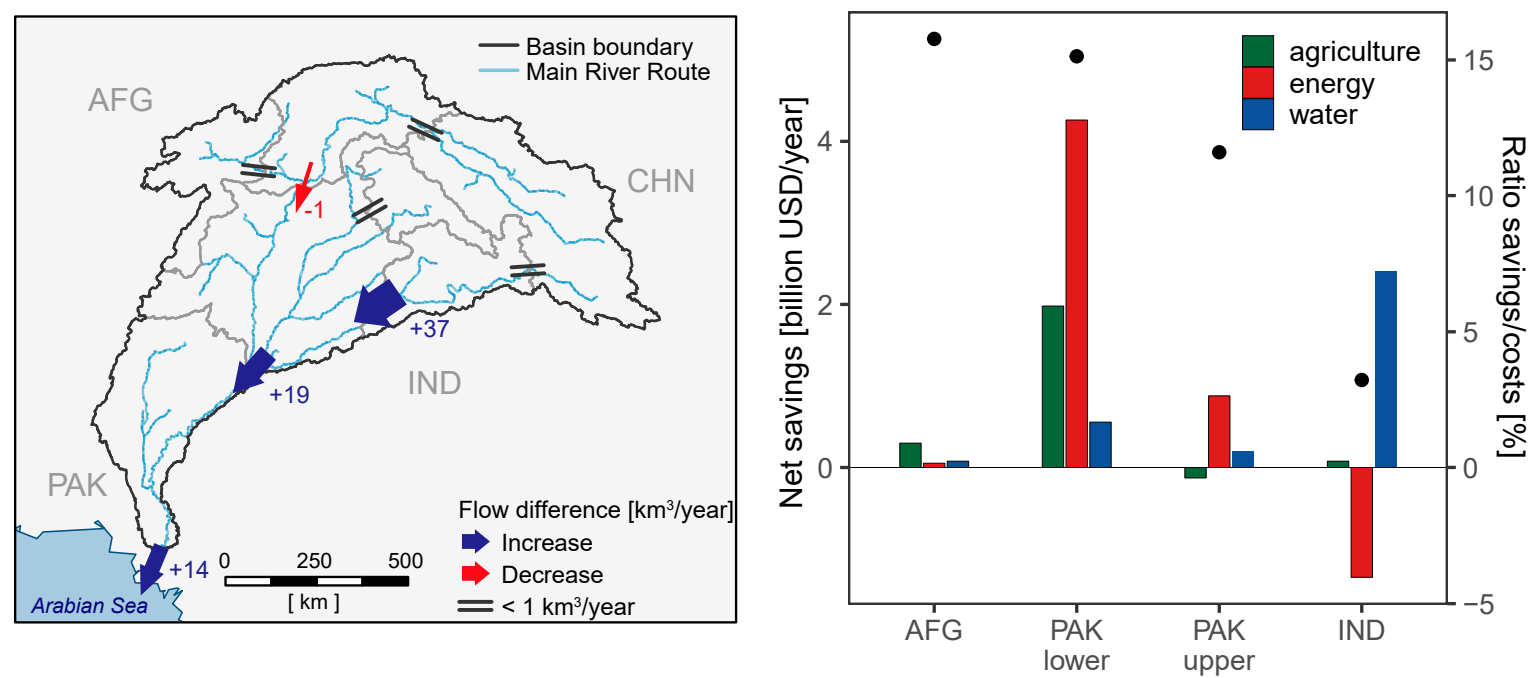

Figure 4: Comparison of electricity generation and transmission (pink arrows) in 2050 in by region for $S D G$ and $S D G$-coop scenarios (a); Comparison of agriculture production and trade (b); Differences in river flow changes in 2050 in the SDG-coop scenario (c); Sectoral annual savings (cost \pm trade) implied with cooperation (bars) and the ratio ravings/costs per each region (black dots, right axis) (d) 
A cooperative scenario without basin-wide food market cooperation ( $S D G-N L$-coop, Table SI 4 ) is still cheaper than the SDG scenario, albeit only $7 \%$, instead of $9 \%$ and, at the same time, would lead to more evenly distributed savings among riparian countries, see Tables S[2 and S] 3 , We tested an additional cooperation scenario without basin electricity market (SDG-NE-coop). This could be the case in which downstream provinces were reluctant, due to climate uncertainty, to delocalize solar energy production in favor of importing hydro-electric energy from upstream regions or neighboring countries [48]. We notice the same changes in basin cost as in the SDG-NL-coop scenario, but with different distribution between regions.

Similarly, the Business-as-usual scenario with multi-sectoral cooperation (BAU-coop) but in the absence of sustainable development policies, has economic advantages even more significant than for the SDG scenario, with about $12 \%$ cost reduction and net savings ranging between $6 \%$ and $20 \%$ between countries (Table S]2).

The results depend on climatic parameters for which there is a high uncertainty such as precipitation patterns and glacier melt. These uncertainties propagate to the prediction of water trends in the coming decades [49, 50]. For the Indus basin, climate change impact on water availability is particularly important but and yet highly uncertain [51]. Based on the knowledge that 60-70\% of discharge in the Indus originates from mountain snow or glacier melt [52], we test the system robustness to a hypothetical extreme scenario of reduced water availability with (SDG-GM-coop) and without cooperation (SDG-GM, Figure SI4). A system robust to extreme reductions in melt-water availability requires additional cost to achieve the SDGs (+7 billion USD/year). Nevertheless, cooperation can still help reduce costs by $13 \%$ (Table SI2). Climate change uncertainty in the Indus basin is a complex topic that requires further analysis and testing of a broader range of sensitivity cases.

Although several policy limitations have been considered to explore main uncertainty dimensions (see also the parametric sensitivity analysis in Supplementary Discussion), possible implementation requires further assessment and planning. In particular, in a transboundary context, large scale crop shift, while not a novelty in Punjabi and Indian agriculture [53, 54], have implications on employment, food market and land use change which need to be reflected in any negotiation process. Socio-cultural aspects such as employment, wages and education -with the exception of water access and energy poverty level- are not included in the modelling framework and deserve 
ad hoc analysis to complement the economic results of this paper.

In conclusion, increasing cooperation around water allocation, energy and food trade appears to always be cost optimal and also environmentally beneficial than non-cooperative strategies. This finding is robust to various levels of cooperation, future scenarios and climatic uncertainty, as well as to changes in crops water requirements and crop yields (see sensitivity analysis, Tables S12 and S(3). Cooperation has the potential to usher important changes in the economic balances and relationships between countries. In this case of the Indus basin, our results show for example how increasing trade and sharing of resources have the potential to improve production while also providing higher river flow to regions that suffer water scarcity for the benefit of all. Policies paving the way for such cooperation should be pursued even with limited crop shift that are politically and socially challenging to implement.

\section{Methods}

This analysis is done with the NExus Solution Tool (NEST), an integrated model for Waterenergy-land-climate systems analysis under global change. The framework links a distributed hydrological model (CWatM, [55]) to an engineering-economic resource supply planning and capacity expansion model (MESSAGEix, [56]), both capturing the historical period and a future time horizon. A detailed and comprehensive description of the model, data requirements and online availability is provided in Vinca et al. 2020 [37]. A brief summary of the main framework is as follows.

The Community Water Model (CWatM) provides a grid-based representation of terrestrial hydrology, applied in this instance at a spatial resolution of 5 arc-minutes (grid-cells approximately $8 \mathrm{~km}$ wide near the equator) and daily temporal resolution. The model can simulate either naturalized streamflow or streamflow impacted by human activities including reservoirs, irrigation demand, and water withdrawals and return flows by industrial and domestic sectors. Sectoral coverage is harmonized between CWatM and MESSAGEix so that demand profiles can be translated between models. CWatM is initially run under baseline conditions to inform MESSAGEix of dynamic constraints on water availability, hydropower potential and irrigation water requirements.

MESSAGEix is a bottom-up systems optimization model that includes resource consumption and capacity limitations at the technology level. MESSAGEix is based on the original MESSAGE 
model that has been developed and applied widely over the past three decades to analyze scenarios of energy system transformation, both globally and in different geographic regions, under technical-engineering constraints and political-societal considerations, e.g., [57-60]. Each technology modeled in MESSAGEix is defined and characterized by input/output efficiencies (rate of commodity consumptions/production during technology operation), economic costs, and environmental impacts (e.g., greenhouse gas emissions, water consumption, etc.). A technology can represent any process that involves resources and commodities, such as power production, energy consumption and irrigation, but can also represent natural systems such as rivers, aquifers and crops. MESSAGEix minimizes the total cost for system capacity and operation over a future time period while meeting exogenous and endogenous demands and technical/policy constraints, as a deterministic inter-regional and inter-temporal linear programming (LP) problem:

$$
\min f(\mathbf{x})=\sum_{r, t} \mathbf{c}_{r, t}^{\mathrm{T}} \mathbf{x}_{r, t} \delta_{t} ; \mathbf{A} \mathbf{x} \geq \mathbf{b}
$$

where $\mathbf{x}$ is the solution vector containing the capacity and operation of any water, energy or agriculture technology in the time period $t$ and region $r$. Economic costs are described in the cost coefficient vector of the objective function c. The discount rate associated with future cash flows is represented by $\delta$. A right-hand side constraints vector $\mathbf{b}$ include the supply-demand balances, capacity limits, technology retirements and capacity additions, and all constraints that express specific policies.

By linking the inputs and outputs of individual processes, energy, water and land decisions can be represented as a single system using the MESSAGEix modeling scheme. Thus, decisions impacting system design and operation over the planning horizon are made understanding the nexus interactions, and will adapt the transformation pathways for each sector to avoid constraints and reduce trade-offs from the perspective of the objective function. Moreover, MESSAGEix supports spatially-distributed systems modeling using a node-link representation, where commodities can be transferred between nodes based on the definition of dedicated technologies. It is therefore possible to explicitly represent the interplay between up- and downstream water users.

For implementation in MESSAGEix, the Indus River Basin is delineated into 24 Basin Country Units (BCUs) using the basin and country administrative boundary datasets. This is a common 
method in spatial water assessment, however it is worth noting that different spatial aggregation choices, in particular those taking into account agro-ecological zones, might impact results [61]. Further disaggregation into the agro-ecological zones is not pursued in this case because of limited spatial variability in crop potential within the delineated BCUs. The planning horizon considers investment periods spanning 2020 to 2050 in 10 year time steps, and 2015 is parameterized as the base historical year (i.e., the initial starting point). Monthly sub-annual time steps are considered. However, a different temporal scale could be used. For instance a daily representation of energy demand and supply could help capture renewable energy variability, but would on the other hand significantly increase running time.

The NEST model adds to a number of similar CLEW models that have been applied to river basins for policy assessment [30, 62-66]. Among these models, only few integrate multiple sectors in one optimization framework, instead of soft linking different optimization tool for each sector [65]. NEST stands out as one of these models that also includes spatial explicit river flow representation, essential to assess upstream and downstream river basin dynamics. The representation of CLEW sectors builds mostly on open global data, facilitating transferability to other geographical regions and the definition of Basin-Country-Units (BCUs) embedding geopolitical borders. Additional local data can substitute or complement global data in empowering the model, facilitating calibration and validation and for building stakeholder trust. A detailed representation of alternative water options, as well as standards of water sanitation is a feature mostly missing in the above-mentioned CLEW models.

Critical areas for possible future improvement include: testing different spatial resolutions and capability to deal with ultra-high resolution data; iterating MESSAGEix and CWatM to obtain a dynamic solution and better representation the non-linear interactions between groundwater and surface water; and, improved assumptions at the geographical (and model) boundaries, for instance with cost curves or market models for food and electricity to represent the options of international trade. Static cost and efficiency assumptions would ideally also be replaced by reasonable projection to capture system learning and improvements. Finally, as mentioned in previous sections, a thorough discussion of socio-cultural policy and implementation aspects deserve assessment with ad hoc methods, as these aspects are often not well addressed in IAMs. 


\section{Cost calculations and assumptions}

The sectoral investment and Operational \& Maintenance costs (in USD2010) discussed in this analysis are calculated in MESSAGEix as multiplication of investment, fixed and variable unit cost by the capacity and utilization factors of each technology/process, which are decision variables of the optimization model.

More details on MESSAGEix formulas are available in [56], while a comprehensive description of all the technologies and processes in NEST is reported by [37]. From this paper, the main cost assumption of all the technologies represented in the model are reported in Tables S] $[5]$ and SI 6 .

The mean annual costs presented in this article and Figure $3 \mathrm{a}$ and Table SI 2 are the average between 2020 and 2050 of total annual investments and O\&M costs.

The net savings presented in Figure $4 \mathrm{~d}$ and Table $S \sqrt{3}$ refer to the total cost summed with the net costs (or earnings) of food products and energy trade. The saving is then the difference in this value between non-cooperative and cooperative scenario. The associated ratio between the total saving and the total cost in the non-cooperative scenarios gives an idea of the relative economic benefit.

Water-energy-land indicators

\section{Water Stress Index (WSI)}

The annual Water Stress Indicator (WSI) compares the overall withdrawals (from any water source) to the Mean Annual Runoff (MAR), which includes the total freshwater inflow. This gives a sense of sustainability of the withdrawals and reliance on non-renewable sources of water [67].

$$
\text { WSI }=\frac{\text { Withdrawals }}{M A R}
$$

\section{Average Food Cost}

The indicator shown in Figure $1 \mathrm{~d}$ in incremental terms is the annual mean of rice and wheat prices for the whole basin. These are calculated as average of regional prices weighted on the regional production (both outputs of the supply demand balance of the optimization model).

\section{Water Price}

Figure $1 \mathrm{~d}$ shows water price in incremental terms, this is calculated as the yearly average basin price as output of the model freshwater supply and demand balance. 


\section{Greenhouse Gas Emissions}

The GHG emission indicator displayed in Figures $1 \mathrm{~d}$ and 3 represent the basin cumulative GHG $\left(\mathrm{CO}_{2}, \mathrm{CH}_{4}\right.$ and $\left.\mathrm{N}_{2} \mathrm{O}\right)$ emission from 2020 in $\mathrm{CO}_{2}$ equivalent terms for the electricity sector and land use.

\section{Air Pollutants}

The Air Pollutants indicator assesses the basin cumulative air pollutants' emissions from electricity generation and land use $\left(\mathrm{SO}_{2}, \mathrm{CO}, \mathrm{NH}_{3}\right.$, VOC) from 2020.

\section{Irrigation Groundwater and Surface Water Intensity (IWI)}

The IWI indicators show the surface and groundwater withdrawals use per unit of crop product, as annual mean of values from each region:

$$
I W I_{s, g}=\text { mean }\left(\frac{I W(r)_{s, g}}{\text { tot_prod }(r)}\right)
$$

where $I W(r)_{s, g}$ for region $r$ is the overall annual irrigation water withdrawal by source; tot_prod is the sum of all crop regional production $s$ and $g$ refer to surface and groundwater.

\section{Land Pollutants}

The Land Pollutants indicator assesses the basin cumulative release of pollutant $\left(\mathrm{K}_{2} \mathrm{O}, \mathrm{N}, \mathrm{N}_{2} \mathrm{O}, \mathrm{P}_{2} \mathrm{O}_{5}, \mathrm{VOC}\right)$ during agriculture activity from 2020 average.

\section{People Without Sanitation Access}

Number of people in the basin that do not have access to sanitation in their household in a specific year.

\section{River Depletion}

The River Depletion indicator in Figure 3c shows the difference between the minimum river flow level (basin annual mean) and river flow of other scenarios, including the reference point of the minimum environmental flow requirement. The reported value is the largest difference.

\section{Modelling scenarios assumptions}

The future scenarios considered in this article represent the technological and earth system transformation pathway under given input data assumptions. In line with the scenario narratives framing climate (Representative Concentration Pathways (RCP)) and human development trajectories (population, GDP, demand profiles for specific sectors from the Shared Socioeconomic Path- 
ways (SSP)) for this analysis we consider SSP2, also called 'middle of the road' and RCP 6.0, which consider warming in 2100 up to three Celsius degrees [68, 69]. Other important assumptions in common among all scenarios are listed in Table S[1.

\section{Full results consultation and visualization}

The results presented in this article explore only a small portion of the model outputs from our scenario analysis. The ISWEL Nexus Basin Scenario Explorer hosted by IIASA provides access to a database of all variables of interest, defined for each scenario and broken down to sub-basin catchments spatial resolution (https://data.ene.iiasa.ac.at/nexus-basins/). The Scenario Explorer is a versatile open access tool to browse, visualize and download data and results. User can freely create a private workspace where customized plots can be saved and shared.

\section{Data availability}

Processed input data used for model runs that support the findings of this study, and associated model code, is publicly available online (in the .RData format) at https://github.com/iiasa/ NEST. Raw data availability is in some cases subjected by third party restrictions. Data are however available from the corresponding author upon request, upon third party permission, when applies.

\section{Code availability}

Model code updated to the scenarios described in this publication is also available for download at https://doi .org/10.5281/zenodo.4037884

\section{References}

\section{References}

[1] Laghari, A. N., Vanham, D. \& Rauch, W. The Indus basin in the framework of current and future water resources management. Hydrology and Earth System Sciences 16, 1063-1083 (2012). URL https: //www.hydrol-earth-syst-sci.net/16/1063/2012/.

[2] Wada, Y. et al. Co-designing Indus Water-Energy-Land Futures. One Earth 1, 185-194 (2019). URL https://doi.org/10.1016/j.oneear.2019.10.006. 
[3] AQUASTAT. Transboundary River Basin Overview -Indus (2011). URL http://www . fao. org/aquastat/en/countries-and-basins/transboundary-river-basins/indus.

[4] Aslam, M. Agricultural productivity current scenario, constraints and future prospects in Pakistan. Sarhad Journal of Agriculture 32(4), 289-303.

[5] Karimi, P., Bastiaanssen, W. G. M., Molden, D. \& Cheema, M. J. M. Basin-wide water accounting based on remote sensing data: an application for the Indus Basin. Hydrology and Earth System Sciences 17, 2473-2486 (2013). URL https://www. hydrol-earth-syst-sci.net/17/2473/2013/.

[6] Akhter, M. The Political Ecology of the Water Scarcity/Security Nexus in the Indus Basin: Decentering Per Capita Water Supply. 21-33 (Springer, Cham, 2017). URL http://link. springer.com/10.1007/978-3-319-32845-4\{_\}2.

[7] Yu, W. et al. Indus Basin of Pakistan : Impacts of Climate Risks on Water and Agriculture. World Bank Publications (2013). URL https://ideas.repec.org/b/wbk/wbpubs/ 13834.html.

[8] Cheema, M., Immerzeel, W. \& Bastiaanssen, W. Spatial Quantification of Groundwater Abstraction in the Irrigated Indus Basin. Groundwater 52, 25-36 (2014). URL http:// doi.wiley.com/10.1111/gwat.12027.

[9] Syvitski, J. P. et al. Anthropocene metamorphosis of the Indus Delta and lower floodplain. Anthropocene 3, 24-35 (2013). URL https : //www. sciencedirect.com/science/ article/pii/S2213305414000058.

[10] Adeel, Z. \& Wirsing, R. G. Imagining Industan Overcoming Water Insecurity in the Indus Basin Introduction. In Adeel, $\mathrm{Z}$ and Wirsing, R. (ed.) IMAGINING INDUSTAN: OVERCOMING WATER INSECURITY IN THE INDUS BASIN, Water Security in a New World, 3-20 (SPRINGER INTERNATIONAL PUBLISHING AG, 2017). URL http://link. springer.com/10.1007/978-3-319-32845-4\{_\}1.

[11] Raman, D. Damming and Infrastructural Development of the Indus River Basin: Strengthening the Provisions of the Indus Waters Treaty. Asian Journal of International Law 
8, 372-402 (2018). URL https://www.cambridge.org/core/product/identifier/ S2044251317000029/type/journal\{_\}article.

[12] Archer, D. R., Forsythe, N., Fowler, H. J. \& Shah, S. M. Sustainability of water resources management in the Indus Basin under changing climatic and socio economic conditions. Hydrology and Earth System Sciences 14, 1669-1680 (2010). URL http://www. hydrol-earth-syst-sci.net/14/1669/2010/.

[13] Just, R. E. \& Netanyahu, S. Conflict and Cooperation on Trans-Boundary Water Resources (Springer US, 1998).

[14] Qamar, M. U., Azmat, M. \& Claps, P. Pitfalls in transboundary Indus Water Treaty: a perspective to prevent unattended threats to the global security. npj Clean Water 2, 1-9 (2019).

[15] Grill, G. et al. Mapping the world's free-flowing rivers. Nature 569, 215-221 (2019).

[16] Wu, X. \& Whittington, D. Incentive compatibility and conflict resolution in international river basins: A case study of the Nile Basin. Water Resources Research 42 (2006). URL http://doi.wiley.com/10.1029/2005WR004238.

[17] Keskinen, M. et al. The Water-Energy-Food Nexus and the Transboundary Context: Insights from Large Asian Rivers. Water 8, 193 (2016). URL http://www .mdpi .com/2073-4441/ $8 / 5 / 193$.

[18] Sustainable Development Goals .. Sustainable Development Knowledge Platform. URL https://sustainabledevelopment .un.org/?menu=1300.

[19] Bhaduri, A. et al. Achieving Sustainable Development Goals from a Water Perspective. Frontiers in Environmental Science 4, 64 (2016). URL http://journal.frontiersin. org/article/10.3389/fenvs.2016.00064/full.

[20] Integrated analysis of climate change, land-use, energy and water strategies. Nature Climate Change 3, 621-626 (2013). URL http://www . nature.com/articles/nclimate1789.

[21] Liu, J. et al. Nexus approaches to global sustainable development (2018). 
[22] Bleischwitz, R. et al. Resource nexus perspectives towards the United Nations Sustainable Development Goals. Nature Sustainability 1, 737-743 (2018). URL http://www . nature. com/articles/s41893-018-0173-2.

[23] Albrecht, T. R., Crootof, A. \& Scott, C. A. The Water-Energy-Food Nexus: A systematic review of methods for nexus assessment. Environmental Research Letters 13, 043002 (2018). URL http://stacks .iop.org/1748-9326/13/i=4/a=043002?key=crossref . $5 f d c 0 b 22 e 55 e 693 f 67397 d 1 d d 74 f a f 0 b$.

[24] Kaddoura, S. \& El Khatib, S. Review of water-energy-food Nexus tools to improve the Nexus modelling approach for integrated policy making. Environmental Science $\mathcal{E}$ Policy 77, 114-121 (2017). URL https://www.sciencedirect.com/science/article/pii/ S1462901117305403.

[25] Siddiqi, A. \& Wescoat, J. L. Energy use in large-scale irrigated agriculture in the Punjab province of Pakistan. Water International 38, 571-586 (2013). URL http://www. tandf online.com/doi/abs/10.1080/02508060.2013.828671.

[26] Stewart, Joel; Podger, Geoff; Ahmad, Mobin; Shah, Syed Mehr Ali; Bodla, Habib; Khero, Zarif; Rana, M. K. I. Indus River System Model (IRSM) - a planning tool to explore water management options in Pakistan: model conceptualisation, configuration and calibration. Tech. Rep., Australia: CSIRO Land \& Water (2018). URL https://publications. csiro.au/rpr/pub?list=SEA $\{\&\}$ pid=csiro:EP186945.

[27] Yang, Y.-C. E., Brown, C. M., Yu, W. H. \& Savitsky, A. An introduction to the IBMR, a hydro-economic model for climate change impact assessment in Pakistan's Indus River basin. Water International 38, 632-650 (2013). URL http: //www . tandf online.com/doi/abs/ $10.1080 / 02508060.2013 .830691$.

[28] Yang, Y. C. E., Ringler, C., Brown, C. \& Mondal, M. A. H. Modeling the Agricultural Water-Energy-Food Nexus in the Indus River Basin, Pakistan. Journal of Water Resources Planning and Management 142, 04016062 (2016). URL http://ascelibrary.org/doi/ 10.1061/ \{\%\}28ASCE $\{\%\} 29 W R$. 1943-5452.0000710. 
[29] Water - Home. URL http://www .unece.org/env/water/nexus.

[30] de Strasser, L., Lipponen, A., Howells, M., Stec, S. \& Bréthaut, C. A Methodology to Assess the Water Energy Food Ecosystems Nexus in Transboundary River Basins. Water 8, 59 (2016). URL http: //www .mdpi . com/2073-4441/8/2/59.

[31] Parrachino, I., Dinar, A. \& Patrone, F. Cooperative Game Theory And Its Application To Natural, Environmental, And Water Resource Issues : 3. Application To Water Resources. Policy Research Working Papers (The World Bank, 2006). URL http://elibrary . worldbank. org/doi/book/10.1596/1813-9450-4074.

[32] Long, N. V. Dynamic Games in the Economics of Natural Resources: A Survey. Dynamic Games and Applications 1, 115-148 (2011). URL http: //link . springer . com/10 .1007/ s13235-010-0003-2.

[33] Singh, A., Jamasb, T., Nepal, R. \& Toman, M. A. Cross-border electricity cooperation in South Asia (2015).

[34] Hasson, R., Löfgren, Å. \& Visser, M. Climate change in a public goods game: Investment decision in mitigation versus adaptation. Ecological Economics 70, 331-338 (2010).

[35] Dalin, C., Wada, Y., Kastner, T. \& Puma, M. J. Groundwater depletion embedded in international food trade. Nature 543, 700-704 (2017).

[36] Kalair, A. R. et al. Water, energy and food nexus of Indus Water Treaty: Water governance. Water-Energy Nexus 2, 10-24 (2019).

[37] Vinca, A. et al. The NExus Solutions Tool (NEST) v1.0: an open platform for optimizing multi-scale energy\&amp;\#8211;water\&amp;\#8211;land system transformations. Geoscientific Model Development 13, 1095-1121 (2020). URL https ://www .geosci-model-dev. net/13/1095/2020/.

[38] Mir, K. A., Purohit, P. \& Mehmood, S. Sectoral assessment of greenhouse gas emissions in Pakistan. Environmental Science and Pollution Research 24, 27345-27355 (2017). URL http://link.springer.com/10.1007/s11356-017-0354-y. 
[39] Ahmad, B. \& Saqlain, S. People perception regarding possible impact of urbanization on environmental degradation in islamabad. IAU International Journal of Social Sciences $\mathbf{8}$, 1-10 (2018). URL http://ijss.srbiau.ac.ir/article\{_\}13724.html.

[40] Scott, C. A., Vicuña, S., Blanco-Gutiérrez, I., Meza, F. \& Varela-Ortega, C. Irrigation efficiency and water-policy implications for river basin resilience. Hydrology and Earth System Sciences 18, 1339-1348 (2014). URL https://www.hydrol-earth-syst-sci.net/18/ $1339 / 2014 /$.

[41] Grafton, R. Q. et al. The paradox of irrigation efficiency. Science 361, 748-750 (2018). URL https://doi.org/10.1126/science.aat9314.

[42] Baum, R., Luh, J. \& Bartram, J. Sanitation: A global estimate of sewerage connections without treatment and the resulting impact on MDG progress. Environmental Science and Technology 47, 1994-2000 (2013).

[43] HydroSHEDS. URL https://hydrosheds.org/

[44] González-villareal, F. \& Schultz, B. FINAL REPORT OF IPOE FOR REVIEW OF STUDIES ON WATER ESCAPAGES BELOW KOTRI BARRAGE E-mail Version FINAL REPORT OF IPOE FOR REVIEW OF STUDIES ON Fernando J Gonzalez Thinus Basson Bart Schultz Delft, the Netherlands 20th of November 2005 (2018).

[45] Casillas, C. E. \& Kammen, D. M. The energy-poverty-climate nexus (2010).

[46] GDP (current US\$) - Pakistan | Data. URL https://data.worldbank.org/indicator/ NY.GDP.MKTP.CD?locations=PK.

[47] Singh, A., Jamasb, T., Nepal, R. \& Toman, M. Electricity cooperation in South Asia: Barriers to cross-border trade. Energy Policy 120, 741-748 (2018).

[48] Rasul, G., Neupane, N., Hussain, A. \& Pasakhala, B. Beyond hydropower: towards an integrated solution for water, energy and food security in South Asia. International Journal of Water Resources Development 1-25 (2019). URL https://www.tandfonline.com/ doi/full/10.1080/07900627.2019.1579705. 
[49] Lutz, A. F., Immerzeel, W. W., Kraaijenbrink, P. D., Shrestha, A. B. \& Bierkens, M. F. Climate change impacts on the upper indus hydrology: Sources, shifts and extremes. PLoS ONE 11, e0165630 (2016).

[50] Maurer, J. M., Schaefer, J. M., Rupper, S. \& Corley, A. Acceleration of ice loss across the Himalayas over the past 40 years. Science Advances 5, eaav7266 (2019).

[51] Immerzeel, W. W., Van Beek, L. P. \& Bierkens, M. F. Climate change will affect the asian water towers. Science 328, 1382-1385 (2010).

[52] Biemans, H. et al. Importance of snow and glacier meltwater for agriculture on the IndoGangetic Plain. Nature Sustainability 2, 594-601 (2019). URL http://www . nature.com/ articles/s41893-019-0305-3.

[53] Singh, A. Agricultural Production and Cropping Pattern Change in India (2015).

[54] Majhi, B. \& Kumar, A. Changing Cropping Pattern in Indian Agriculture. Journal of Economic $\mathcal{F}$ Social Development XIV, No. 1 (2018). URL http://www . iesd.org. in/jesd/ Journalpdf /2018-XIV-1ChangingCroppingPatterninIndianAgriculture.pdf

[55] Burek, P. et al. Development of the Community Water Model (CWatM v1.04) A highresolution hydrological model for global and regional assessment of integrated water resources management. Geoscientific Model Development Discussions 1-49 (2019). URL https://www.geosci-model-dev-discuss.net/gmd-2019-214/.

[56] Huppmann, D. et al. The MESSAGEix Integrated Assessment Model and the ix modeling platform (ixmp): An open framework for integrated and cross-cutting analysis of energy, climate, the environment, and sustainable development. Environmental Modelling $\mathcal{F}$ Software 112, 143-156 (2019). URL https://www.sciencedirect.com/science/article/pii/ S1364815218302330.

[57] Messner, S. \& Strubegger, M. User's Guide for MESSAGE III (1995).

[58] Riahi, K., Grübler, A. \& Nakicenovic, N. Scenarios of long-term socio-economic and environmental development under climate stabilization. Technological Forecasting and Social Change 74, 887-935 (2007). 
[59] Van Vliet, O. et al. Synergies in the Asian energy system: Climate change, energy security, energy access and air pollution. Energy Economics 34, S470-S480 (2012).

[60] Kiani, B. et al. Optimal electricity system planning in a large hydro jurisdiction: Will British Columbia soon become a major importer of electricity? Energy Policy 54, 311-319 (2013).

[61] Salmivaara, A. et al. Exploring the Modifiable Areal Unit Problem in Spatial Water Assessments: A Case of Water Shortage in Monsoon Asia. Water 7, 898-917 (2015). URL http://www.mdpi.com/2073-4441/7/3/898.

[62] Kahil, T. et al. A continental-scale hydroeconomic model for integrating water-energy-land nexus solutions. Water resources research (2018).

[63] Kim, S. H. et al. Balancing global water availability and use at basin scale in an integrated assessment model. Climatic Change 136, 217-231 (2016).

[64] Payet-Burin, R., Kromann, M., Pereira-Cardenal, S., Strzepek, K. M. \& Bauer-Gottwein, P. WHAT-IF: an open-source decision support tool for water infrastructure investment planning within the water-energy-food-climate nexus. Hydrology and Earth System Sciences 23, 4129-4152 (2019). URL https://www .hydrol-earth-syst-sci.net/23/4129/2019/.

[65] Sridharan, V., Shivakumar, A., Niet, T., Ramos, E. P. \& Howells, M. Land, energy and water resource management and its impact on GHG emissions, electricity supply and food production- Insights from a Ugandan case study. Environmental Research Communications 2, 085003 (2020).

[66] Saif, Y. \& Almansoori, A. An Optimization Framework for the Climate, Land, Energy, and Water (CLEWS) Nexus by a Discrete Optimization Model 105, 3232-3238 (2017).

[67] Smakhtin, V. U., Revenga, C. \& Doll, P. Taking into account environmental water requirements in global-scale water resources assessments. IWMI Research Reports (2004).

[68] Van Vuuren, D. P. et al. The representative concentration pathways: An overview. Climatic change 109, 5 (2011). 
[69] O’Neill, B. C. et al. The roads ahead: Narratives for shared socioeconomic pathways describing world futures in the 21st century. Global Environmental Change 42, 169-180 (2017).

The corresponding author for this manuscript is Adriano Vinca.

\section{Acknowledgments}

The authors acknowledge the Global Environment Facility (GEF) for funding the development of this research as part of the Integrated Solutions for Water, Energy, and Land (ISWEL) project (GEF Contract Agreement: 6993), and the support of the United Nations Industrial Development Organization (UNIDO). The research has also been supported by the University of Victoria's Building Connections internal grant, the Natural Sciences and Engineering Research Council of Canada. The authors would like to acknowledge and thank Astrid Hillers, Robert Novak, David Grey, Leena Srivastava and Youba Sokona, members of the ISWEL steering committee, for the enthusiasm and support that characterized the whole collaboration.

\section{Author contributions}

AV, SP, AS, AM, AI, PM and KR conceived of the research questions and scenario design. AS, AM, AI, BW, NY and MA helped enrich the regional background of the research. AV and SP led model development. AV led the analysis of results, the preparation of figures, data tables and online repositories, and the writing of the manuscript. All the authors contributed to review the manuscript.

\section{Competing Interests}

The authors declare no competing interests. 